\title{
Protective Effect of Spironolactone on Endothelial-to-Mesenchymal Transition in HUVECs via Notch Pathway
}

\author{
Xiao Chen a,b Jiejie Caic Xi Zhou ${ }^{a}$ Lingzhi Chen ${ }^{d}$ Yongsheng Gong ${ }^{\mathrm{a}}$ Zhan Gao \\ Huaiqin Zhang ${ }^{\text {a }}$ Weijian Huang ${ }^{\text {a }}$ Hao Zhou $^{a}$ \\ aDepartment of Cardiology, the First Affiliated Hospital of Wenzhou Medical University, Wenzhou, \\ 'Department of Cardiology, Ningbo First Hospital, Ningbo, 'Department of Coronary Care Unit, The \\ First Affiliated Hospital of Wenzhou medical university, Wenzhou, 'Department of Clinical laboratory, \\ Wenzhou Central Hospital, Wenzhou, eDepartment of Hypoxia Medical Research laboratory, Wenzhou \\ Medical University, Wenzhou China
}

\section{Key Words}

Spironolactone $\bullet$ Fibrosis $•$ EndMT $\bullet$ TGF- $\beta$ • Notch pathway $\bullet$ HUVEC

\begin{abstract}
Background: Fibrosis results in excessive buildup of extracellular matrix proteins along with abnormalities in structure and is partly derived by a process involving transforming growth factor $\beta$ (TGF- $\beta$ ) called endothelial-to-mesenchymal transition (EndMT). We investigated whether the aldosterone receptor-blocker spironolactone could abrogate TGF- $\beta$-induced fibrosis in EndMT and the underlying mechanism. Methods: Human umbilical vein endothelial cells (HUVECs) were divided into 5 groups for treatment: blank; vehicle control; TGF- $\beta$ (10 ng/ $\mathrm{ml})$; spironolactone $(1 \mu \mathrm{M})+$ TGF- $\beta$; and spironolactone+TGF- $\beta+$ DAPT $(10 \mu \mathrm{M})$. Cell chemotaxis was assayed by transwell assay. The expression of CD31 and vimentin was determined by Immunofluorescence staining and western blot analysis. Notch1 protein level was detected by western blot analysis. Results: Spironolactone significantly prevented TGF- $\beta$-stimulated EndMT by down-regulate vimentin and up-regulate CD31 in HUVECs $(p<0.01)$.It inhibited cell migration during EndMT $(p<0.01)$. The protective effect of spironolactone against EndMT could be attenuated by blocking the Notch signal pathway with DAPT $(p<0.01)$. Notch signaling was activated and cross-interacted with TGF- $\beta$ and spironolactone in regulating EndMT in HUVECs and reversed the spironolactone-related signaling by abrogating the antifibrotic actions with decreased Notch1 protein expression $(p<0.01)$. Conclusion: Spironolactone may have a protective role in TGF- $\beta$-induced EndMT in HUVECs mediated by the Notch signal pathway.
\end{abstract}

Hao Zhou

KARGER 125
Department of Cardiology, The First Affiliated Hospital of Wenzhou Medical University, Wenzhou Ouhai Region, Wenzhou city, Zhejiang province (China)

Tel. +86-13-968-801-939, Fax +86-05-775-557-979-6, E-Mail wyzh66@126.com 


\section{Cellular Physiology Cell Physiol Biochem 2015;36:191-200 \\ \begin{tabular}{l|l|l}
\cline { 2 - 2 } DOI: 10.1159/000374063 & (c) 2015 S. Karger AG, Basel
\end{tabular} \\ and Biochemistry Published online: April 30, 2015 \\ www.karger.com/cpb \\ Pathway}

\section{Introduction}

The transdifferentiation and generation of myofibroblasts and fibroblasts, is associated with organism proliferation derived from cell apoptosis, necrosis and intercellular transformation in the whole life cycle of mammals. Fibroblasts and myofibroblasts can produce a mass of extracellular matrix (ECM) by activating numerous biological mediators; partial fibroblast cells can transform into myofibroblasts and secrete the characteristic $\alpha$-smooth muscle actin ( $\alpha$-SMA) alone with overexpression of large amounts of collagen matrix. This continuous secretion status can involve the whole fibrosis process and aggravate fibrosis. Many studies have focused on the biochemical mechanism of the epithelial-to-mesenchymal (EMT) transition and endothelial-to-mesenchymal transition (EndMT), the two basic origins of fibroblasts or myofibroblasts in most fibrosis-related diseases, such as cardiac fibrosis, renal fibrosis, pulmonary fibrosis and hepatic fibrosis $[1,2]$. The EndMT progress can be demonstrated by specific biochemical changes, including decreased expression of endothelial makers, mainly VE-cadherin, CD31, von Willibrand factor (vWF), and increased expression of mesenchymal markers such as vimentin, matrix metalloproteases (MMPs), fibroblast-specific protein 1 (FSP-1), fibronectin and $\alpha$-SMA $[3,4]$.

It is well known that TGF- $\beta$ is the most important mediator that increases the synthesis of matrix proteins and decreases the production of matrix metalloproteinase during fibrosis [5]. TGF- $\beta$ signals through transmembrane receptors, which activate Smad2/3 phosphorylation: in turn, the phosphorylated Smad2/3 complex translocate into the nucleus, where it induces the expression of pro-fibrotic target genes [6, 7].

It is known that the Notch signaling pathway, conserved during evolution, mediates signal transduction between neighboring cells and plays a crucial role in cell proliferation, transdifferentiation and apoptosis. Notch signaling occurs in a highly localized manner by interacting with neighboring cells. When a ligand binds to the Notch receptor, Notch undergoes two proteolytic cleavage events: it liberates the Notch intracellular domain to enter the nucleus, where it binds to the transcription factor RBPJK/CBF1/Su(H) and converts it from a repressor to an activator for target genes, including the Hes and Hey family genes [8]. The Notch signal pathway has attracted much attention in research into fibrosis formation and collagen regeneration. In detecting the relevant signal molecules of the Notch pathway in fibrotic tissue, the downstream transcription factor Hes1 was found downregulated and the ligand Jag1 upregulated [9]. Similar results were observed in vivo. In a mouse model with the Notch signal pathway effectively blocked, $\alpha$-SMA protein expression and collagen staining was increased significantly. The level of TGF- $\beta$, which acts as a mediator to induce EndMT, was increased [10]. Furthermore, Notch signaling can contribute to EndMT in both tumor progression and cardiac development [4]. Notch signaling functions in the TGF- $\beta$-mediated EndMT that occurs during endocardial cushion formation and myocardial fibrosis $[11,12]$.

Studies illustrate activation of the renin-angiotensin-aldosterone system (RAAS) is a risk factor for the development of fibrosis $[13,14]$. Spironolactone is the most common aldosterone receptor antagonist used to pharmacologically block actions of aldosterone and for treatment of congestive heart failure, liver cirrhosis and hypertension. It competitively inhibits the binding of aldosterone to the mineralocorticoid receptor [15]. Spironolactone reduced the combined endpoint of death or hospitalization for heart failure in nonAfrican Americans as compared with African Americans; hyperkalemia was lessened and hypokalemia increased [16]. As well, spironolactone improved cardiac remodeling by reducing proinflammatory cytokine levels and inhibiting TGF- $\beta$ and R-Smads expression [17].

We examined TGF- $\beta$ inducing EndMT in primary cultured human umbilical vein endothelial cells (HUVECs) and possible blockage by spironolactone to investigate the morphologic and functional changes. As well, we determined whether the Notch pathway is involved in the EndMT-driven fibrosis. 


\section{Cellular Physiology Cell Physiol Biochem 2015;36:191-200 \\ \begin{tabular}{l|l} 
and Biochemistry Published online: April 30, 2015 & $\begin{array}{l}\text { C) 2015 S. Karger AG, Basel } \\
\text { www.karger.com/cpb }\end{array}$ \\
\hline
\end{tabular} \\ Chen et al.: Spironolactone Protects HUVECs from EndMT Involvement of the Notch-1 Pathway}

\section{Material and Methods}

\section{Reagents and antibodies}

Reagents of spironolactone and Hoechst 33342 were from Sigma (St. Louis, MO, USA). DyLight 488 goat anti-rabbit IgG $(\mathrm{H}+\mathrm{L})$ and DyLight 594 goat anti-mouse IgG $(\mathrm{H}+\mathrm{L})$ were from Molecular Probes (Life Technologies, USA). Antibodies for rabbit monoclonal anti-vimentin, mouse monoclonal anti-CD31 and anti-Notch1 were from Cell Signaling Technology (Cst, Beverly, MA, USA). $\gamma$-Secretase inhibitor N-3,5difluorophenyl acetyl-Lalanyl-2-phenylglycine-1,1-dimethylethyl ester (DAPT) and recombinant human TGF- $\beta$ were from Roche (Indianapolis, IN, USA). Anti-vWF antibody was from Abcam (Cambridge, MA, USA). Anti- $\beta$-actin was from Bioworld Technology (Nanjing, China).

\section{Cell culture and treatment}

The First Affiliated Hospital of Wenzhou Medical University.

Primary HUVECs were obtained from umbilical cords of randomly selected healthy mothers delivering at the First Hospital affiliated with Wenzhou Medical University after perfusion of umbilical cords with $0.05 \%$ trypsin- $0.03 \%$ EDTA (Invitrogen) for $8 \mathrm{~min}$ at $37^{\circ} \mathrm{C}$. HUVECs were cultured in Endothelial Cell Growth Medium BulletKit-2 (EGM-2, Lonza, USA) at $37^{\circ} \mathrm{C}$ in a humidified atmosphere of $5 \% \mathrm{CO}_{2}$. EGM-2 was supplemented with the bulletkit growth supplement mixture (Lonza) and 10\% fetal bovine serum (FBS; Gibco). The medium was changed every 2 days. When cultures reached about $80 \%$ confluence, adherent cells were detached with $0.05 \%$ trypsin- $0.03 \%$ EDTA for 2 min at $37^{\circ} \mathrm{C}$, washed with PBS, re-suspended in EGM-2 and plated on tissue culture dishes. For all experiments, we used cells between passages 3 and 5. Passage 3 cells were seeded on glass coverslips and assayed for vWF immunophenotype by immunofluorescence to confirm their stromal nature and to test the degree of purity of the cell cultures.

\section{Experimental design}

HUVECs were randomly divided into 5 groups for treatment: blank control; vehicle control (DAPT dissolved in DMSO); TGF- $\beta$ (10 ng/ml); spironolactone $(1 \mu \mathrm{M})+\mathrm{TGF}-\beta$; spironolactone+TGF- $\beta+\mathrm{DAPT}(10$ $\mu \mathrm{M})$. HUVECs were exposed to spironolactone $24 \mathrm{~h}$ before TGF- $\beta$. In selected experiments, cells were treated with DAPT $1 \mathrm{~h}$ before spironolactone.

\section{Transwell assay}

Cell chemotaxis assay involved 24-well cell culture chambers of 6.5-mm diameter with polycarbonate membrane filters including $8-\mu$ m pores (Transwell; Corning). Cells were starved for $12 \mathrm{~h}$, then cell suspension $\left(5 \times 10^{4}\right.$ cells/well $)$ without FBS was added to the upper wells of the inserts. The lower chamber was filled with $600 \mu \mathrm{L}$ medium supplemented with $2 \%$ FBS. Cells were allowed to migrate for $24 \mathrm{~h}$; non-migrated cells were gently wiped with cotton swabs and migrated cells were fixed with ice-cold methanol and stained with crystal violet. The filters were washed with distilled water and images were obtained under an inverted microscope (Olympus). Cells were quantified by manual counting.

\section{Immunofluorescence}

For immunofluorescence assay, HUVECs were incubated with agents as indicated on glass slides in 24well culture plates. After being washed by cold PBS, cells were fixed with $4 \%$ paraformaldehyde, sequentially blocked with solution (Beyotime Institute of Biotechnology) containing 1\% Triton X-100 and cover-slipped, then treated with primary antibody to $\mathrm{CD} 31$ (1:1600 dilution) or vimentin (both Cst: 1:100 dilution) at $4^{\circ} \mathrm{C}$ in a humid chamber overnight, incubated with Alexa Fluor 488 (for CD31) or Alexa Fluor 594 (for Vimentin) conjugated secondary antibody in the dark for $2 \mathrm{~h}$, then counterstained with Hoechst 33342 for nuclei. Cells were mounted on slides and visualized under a fluorescence microscope (ECLIPSE TI, NIKON).

\section{Western blot analysis}

For analysis of protein expression of vimentin, CD31, and Notch1 in HUVECs, cells were homogenized in lysis buffer $(150 \mathrm{~mol} / \mathrm{L} \mathrm{NaCl} ; 2 \mathrm{mmol} / \mathrm{L}$ EDTA; $50 \mathrm{mmol} / \mathrm{L}$ Tris/HCl; $0.2 \%$ Triton X-100; 0.3\% IGEPAL, $2 \mathrm{mmol} / \mathrm{L}$ EGTA; $1 \mathrm{ml} / \mathrm{mL}$ PMSF, 10ml/mL protease inhibitors cocktail; $1 \mathrm{ml} / \mathrm{mL}$ and $10 \mathrm{ml} / \mathrm{mL}$ orthovanadate) and then separated by 10\% SDS-polyacrylamide gel electrophoresis. An equal amount of protein $(40 \mu \mathrm{g} /$ well $)$ were loaded in each lane and transferred onto polyvinylidenedifluoride membranes, 


\section{Cellular Physiology Cell Physiol Biochem 2015;36:191-200

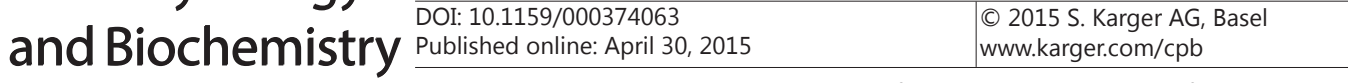 \\ Chen et al.: Spironolactone Protects HUVECs from EndMT Involvement of the Notch-1 Pathway}

which were blocked with non-fat milk for $1 \mathrm{~h}$, then incubated with primary antibodies (anti-CD31 antibody, anti-vimentin antibody and anti-Notch1 antibody, all Cst: $1: 1000$ dilution) at $4{ }^{\circ} \mathrm{C}$ overnight. $\beta$-actin (Bioworld Technology, 1:5000 dilution) was the loading control. Blots were then incubated with anti-rabbit or anti-mouse peroxidase-conjugated secondary antibody (Cst: 1:5000 dilution) for $1 \mathrm{~h}$. Proteins in bands were developed with use of an enhanced chemiluminescence (ECL) kit (Cst). Immunoreactive bands were detected using Chemiluminescent HRP Substrate (Applygen Technologies, Beijing, China), and scans were obtained using the Bio-Rad gel image analysis system (BioRad, Hercules, CA, USA) and processed using Image-Pro Plus (Media Cybernetics, Inc.).

\section{Statistical analysis}

Data are expressed as mean \pm SD. Comparison of means involved ANOVA and least significant difference (LSD) test with SPSS 16.0 (Chicago, IL). P < 0.05 was considered statistically significant.

\section{Results}

Morphological changes and immunofluorescence of HUVECS

We evaluated morphological alterations in HUVECs (Fig. 1) induced by TGF- $\beta$ while reversed by spironolactone. As in the process of EndMT, endothelial cells lost their apical-basal polarity and adhesion, for increased migration and invasiveness, and became spindleshaped and elongated. These features were reversed by spironolactone treatment; they lost the prominent filopodia and fibroblastic shape. With DAPT treatment to block the Notch signal pathway, the morphological changes with spironolactone were abrogated. Primary cultured HUVECs were immunostained with antibodies against vWF (Fig. 1-A). Treatment with the agents was well tolerated, with no differences in morphological, immunophenotypic or other signs.

\section{Spironolactone inhibits cell migration induced by TGF- $\beta$}

Cell migration ability was analyzed by transwell chemotactic assay $24 \mathrm{~h}$ after migrated cells were evaluated and counted (Fig. 2). We examined that the number of permeating septum cells in TGF- $\beta$ group was dramatically increased compared to the control $(\mathrm{P}<0.01)$.
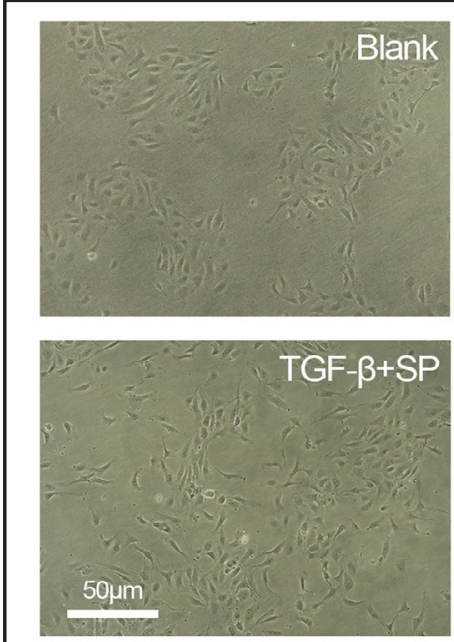
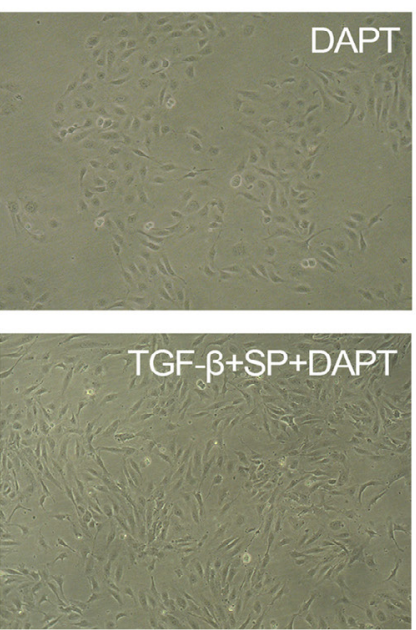
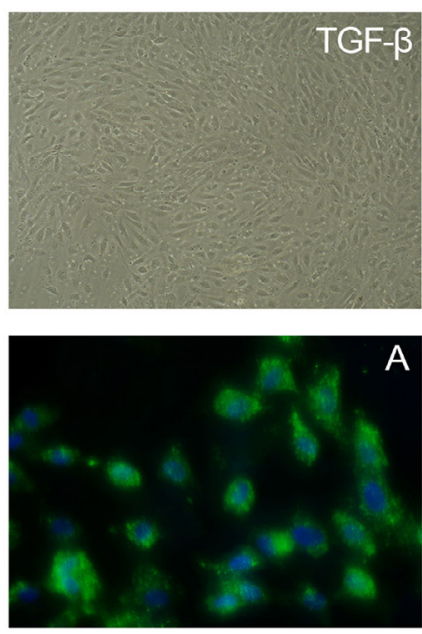

VWF Hoechst33342

Fig. 1. Light microscopy and immunofluorescence of morphological changes in primary cultured HUVECs. Blank; vehicle control (DAPT $10 \mu \mathrm{M})$; TGF- $\beta$ (10 ng/ml) treatment; spironolactone $(1 \mu \mathrm{M})+\mathrm{TGF}-\beta$; spironolactone+TGF- $\beta+$ DAPT $(10 \mu \mathrm{M})$. Immunofluorescence staining of HUVECs for vWF (endothelial phenotype; green) and nuclei with Hoechst 33342 (blue) (A). Magnification $\times 200$.

\section{KARGER}




\section{Cellular Physiology Cell Physiol Biochem 2015;36:191-200 \begin{tabular}{ll|l} 
and Biochemistry & $\begin{array}{l}\text { DOI: 10.1159/000374063 } \\
\text { Published online: April 30, } 2015\end{array}$ & $\begin{array}{l}\text { O 2 2015 S. Karger AG, Basel } \\
\text { www.karger.com/cpb }\end{array}$ \\
\cline { 2 - 3 }
\end{tabular} \\ Chen et al.: Spironolactone Protects HUVECs from EndMT Involvement of the Notch-1 Pathway}

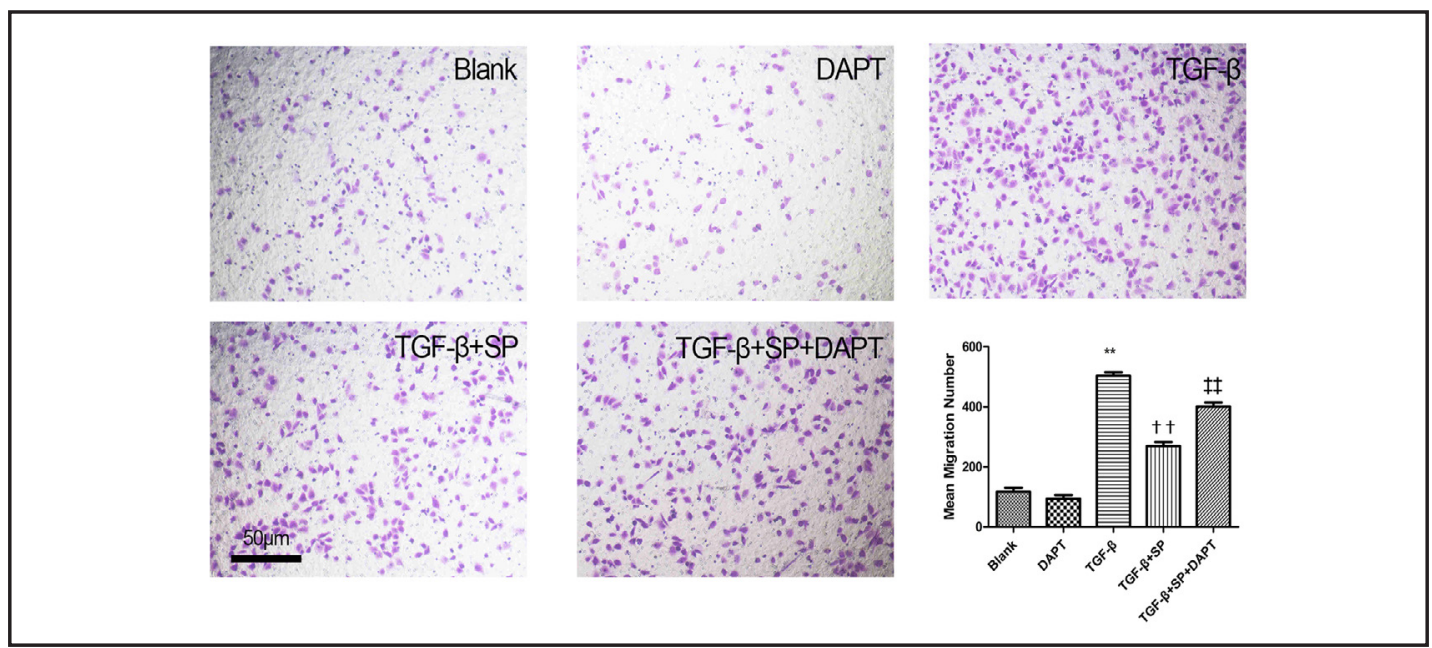

Fig. 2. Spironolactone inhibited cell migration stimulated by TGF- $\beta$, which was attenuated by DAPT. Transwell assay of HUVECs pre-treated with spironolactone (SP; $1 \mu \mathrm{M})$ for $24 \mathrm{~h}$, then TGF- $\beta$ (10 ng/ml), then DAPT $(10 \mu \mathrm{M})$. Shows quantification. Magnification $\times 200 .{ }^{* *} \mathrm{p}<0.01 \mathrm{vs}$. Blank; ${ }^{\top} \mathrm{p}<<0.01 \mathrm{vs}$. TGF- $\beta$; ${ }^{*} \mathrm{p}<0.01$ vs. TGF- $\beta+$ SP.
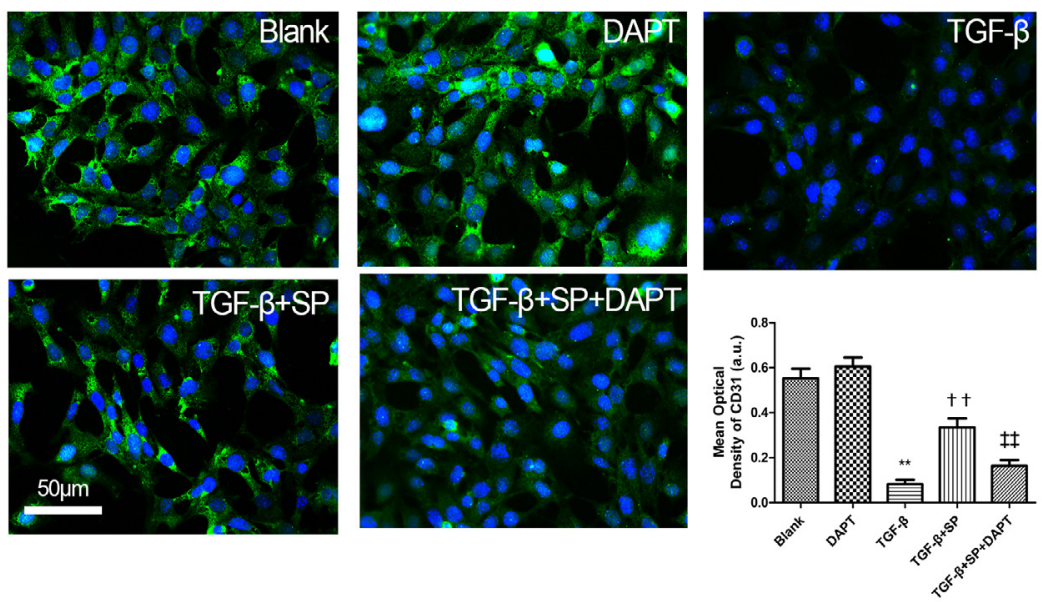

Fig. 3. Fluorescence microscopy of staining with CD31 (endothelial phenotype; green) and Hoechst 33342 (blue) in HUVECs and quantification. Spironolactone (SP, $1 \mu \mathrm{M})$, TGF- $\beta$ (10 ng/ml), DAPT (10 $\mu$ M). Magnification $\times 200{ }^{* *} \mathrm{p}<0.01$ vs. Blank; ${ }^{\top 1} \mathrm{p}<0.01$ vs. TGF- $\beta$; ${ }^{\#} \mathrm{p}<0.01$ vs. TGF- $\beta+S P$.

Spironolactone statistically attenuated the number of migrated cells when pre-cultivated 24 $\mathrm{h}$ before TGF- $\beta(\mathrm{P}<0.01)$. The number of migrated cells was increased after disposed with DAPT compared to TGF- $\beta+$ spironolactone group $(\mathrm{P}<0.01)$.

\section{Spironolactone inhibits TGF- $\beta$-induced EndMT}

In order to determine cell transdifferentiation during EndMT, we examined the change in expression of two biomarkers in each group evaluated by immunofluorescence: upregulation of vimentin and downregulation of CD31. In control HUVECs, Vimentin-positive cells were few, but CD31-positive cells reached the highest intensity (green, Fig. 3). TGF- $\beta$ significantly increased vimentin-positive cells $(\mathrm{P}<0.01$, Fig. 4) while reduced the CD31-positive cells $(\mathrm{P}<0.01$, Fig. 3). Spironolactone reversed the increased expression in vimentin $(\mathrm{P}<0.01$, Fig. 4 ) and also reversed the lessened expression in CD31 ( $<<0.01$, Fig. 3). Spironolactone could significantly inhibit TGF- $\beta$-stimulated EndMT incubation of HUVECs in vitro.

\section{KARGER}




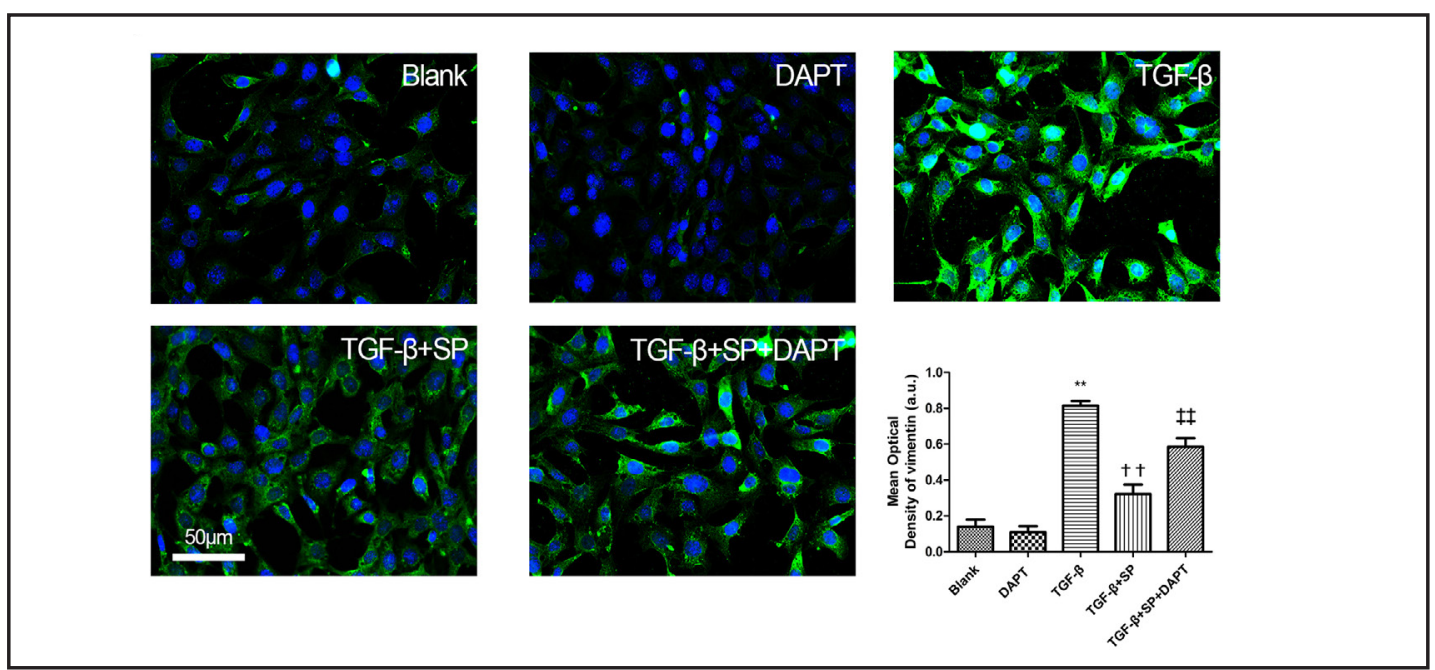

Fig. 4. Fluorescence microscopy of vimentin staining (myofibroblastic phenotype) in HUVECs and nuclei labelled with Hoechst 33342 (blue) and quantification. Magnification $\times 200{ }^{* *} \mathrm{p}<0.01 \mathrm{vs}$. Blank; ${ }^{\top \uparrow} \mathrm{p}<0.01 \mathrm{vs}$. TGF- $\beta$; ${ }^{*} \mathrm{p}<0.01$ vs. TGF- $\beta+$ SP.

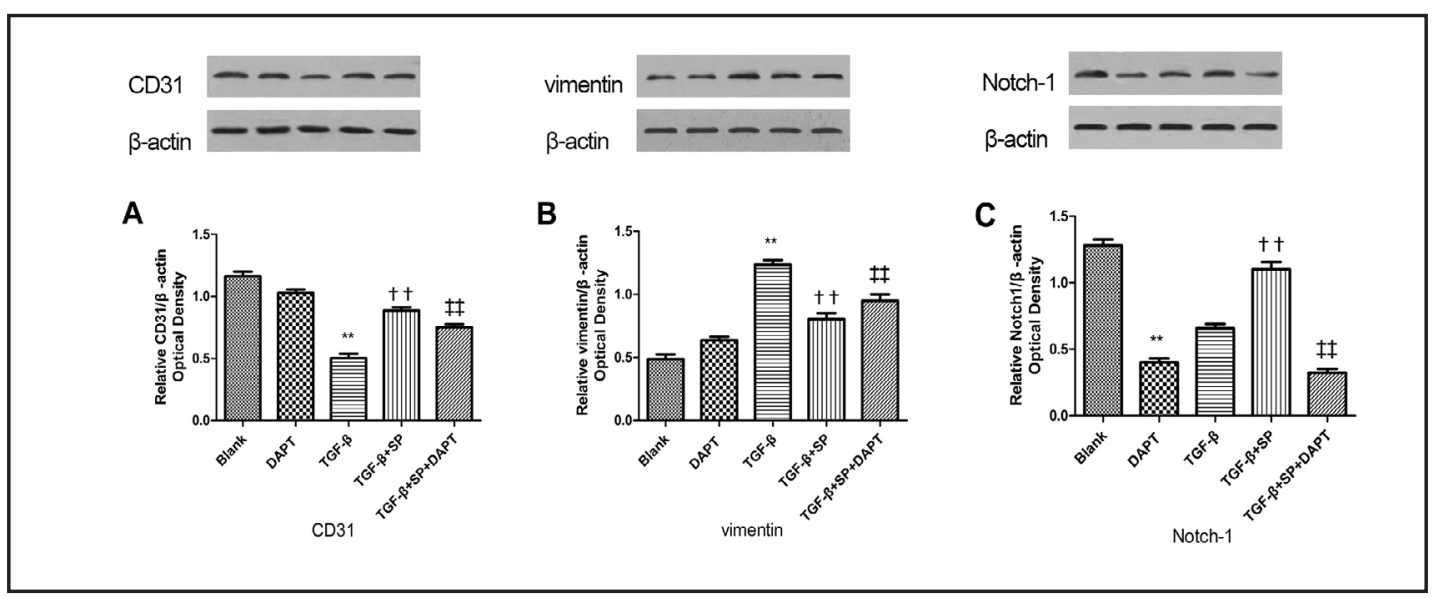

Fig. 5. Spironolactone and Notch-1 negatively regulates EndMT induced by TGF- $\beta$ in HUVECs. Western blot analysis and quantification of CD31 (A), vimentin (B) and Notch-1 (C) expression in HUVECs treated as indicated. Pretreatment with DAPT $(10 \mu \mathrm{M})$ before SP $(1 \mu \mathrm{M})$ for $24 \mathrm{~h}$ and stimulation with TGF- $\beta$ (10 ng/

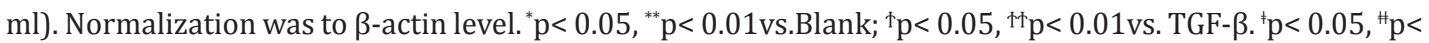
0.01 vs. TGF- $\beta+$ SP.

The results of western blotting showed significant decreased the endothelial-related molecule CD31 was down-regulated with TGF- $\beta$ treatment $(\mathrm{P}<0.01$, Fig. $5-\mathrm{A})$. On the other hand, the mesenchymal-related molecule vimentin was up-regulated induced by TGF- $\beta$ $(\mathrm{P}<0.01$, Fig. 5-B). Pre-incubation with spironolactone reversed the TGF- $\beta$-stimulated EndMT phenotypic changes, for upregulation of $\mathrm{CD} 31(\mathrm{P}<0.01$, Fig. $5-\mathrm{A})$ and downregulation of vimentin $(\mathrm{P}<0.01$, Fig.s 5 -B). Spironolactone could reverse fibrosis by inhibiting the formation of myofibroblasts, fibers and rebuilding intercellular adhesion sites.

Notch inhibitor suppresses TGF- $\beta$-Induced EndMT

To investigate the role of the Notch pathway in fibrosis, transwell analysis showed that spironolactone significantly attenuated TGF- $\beta$-induced endothelial cell migration, which could be abrogated with DAPT treatment ( $\mathrm{P}<0.01$, Fig. 2). Therefore, the Notch inhibitor DAPT could abrogate the effect of spironolactone on cell migration. CD31-positive 


\section{Cellular Physiology Cell Physiol Biochem 2015;36:191-200

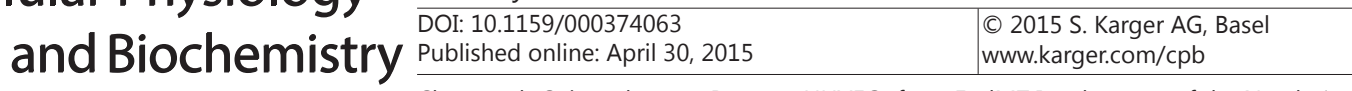 \\ Chen et al.: Spironolactone Protects HUVECs from EndMT Involvement of the Notch-1 Pathway}

cells were significantly lessened when DAPT was disposed into incubation compared to spironolactone + TGF- $\beta$ group $(\mathrm{P}<0.01$, Fig. 3 ). In contrast, vimentin-positive cells were increased in number with DAPT than spironolactone+TGF- $\beta$ group $(\mathrm{P}<0.01$, Fig. 4$)$, so the Notch pathway inhibitor attenuated the protective changes stimulated by spironolactone. By the same token, DAPT decreased the TGF- $\beta$-increased CD31 protein level $(\mathrm{P}<0.05$, Fig. 5 -A $)$ and increased the TGF- $\beta$-decreased vimentin level $(\mathrm{P}<0.05$, Fig. $5-\mathrm{B})$.

\section{Notch inhibitor reverses EndMT in vitro}

Furthermore, to determine whether End MT can be reversed by blocking Notch signaling pathway, we examined Notch1 protein level. Notch1 protein expression was down-regulated in HUVECs treated with TGF- $\beta(\mathrm{p}<0.01$, Fig. $5-\mathrm{C})$, it was increased with spironolactone treatment $(\mathrm{p}<0.01)$ and dramatically down-regulated with DAPT treatment $(\mathrm{p}<0.01)$. Therefore, DAPT blocked TGF- $\beta$-induced EndMT and reduced the decrease in fibrosis in vitro due to aldosterone receptor antagonism with spironolactone. Inhibiting Notch signaling could cause HUVECs to regain their parental phenotype and play an important role in antifibrosis in vitro with spironolactone treatment.

\section{Discussion}

In the present study, we used TGF- $\beta$ to establish a fibrotic model in HUVECs in vitro; spironolactone inhibited the cell migration, phenotypic transformation and collagen synthesis ability induced by TGF- $\beta$. Blocking Notch signaling by a $\gamma$-secretase inhibitor, DAPT, significantly altered fibrosis and abrogated the function of spironolactone by increasing the expression of vimentin, in association with the decreased expression of CD31. Finally, we demonstrated that the Notch pathway was closely related to TGF- $\beta$-induced EndMT in cultured HUVECs and probed related mechanisms underlying the anti-fibrotic action of spironolactone.

EndMT counts about 10 percent sources of myofibroblasts during the development of cardiac, kidney and pulmonary fibrosis. EndMT is a complex biological process whereby endothelial cells lose their specific markers and acquire a mesenchymal or myofibroblastic phenotype, acquire invasive and migratory properties and express mesenchymal cell products such as $\alpha$-SMA and type I collagen $[1,18]$. In vivo, labeled endothelial cells scattered throughout the fibrotic area expressed multiple myofibroblastic phenotypes in mice with aortic banding to induce myocardial fibrosis [19]. Although transformation of EndMT is often linked to fibrosis and adverse consequences, the primary function of fibrosis in tissue could be repair; for example, myocardial infarction is in fact beneficial [20]. However, EndMT has a critical role during malignant transformation and tumor progression, endowing cancer cells with invasive and metastatic properties [21].

TGF- $\beta$ is the key factor regulating the EndMT, which increases the production of extracellular matrices and promotes the fibrosis of cardiac and renal tissues [22]. TGF- $\beta$ can induce endothelial cells to undergo EndMT in mouse cardiac-fibrosis models [18]. In primary cultured HUVECs, we found evidence of mesenchymal-specific cells associated with increased related protein expression dependent on TGF- $\beta$, which led to increased fibrosis. Our cells stimulated with TGF- $\beta$ and treated with the aldosterone receptor-antagonist spironolactone showed a progressive loss and eventual disappearance of endothelial cell markers, including CD31, and a parallel acquisition of mesenchymal-derived cell markers such as vimentin, which suggested that spironolactone could abrogate the TGF- $\beta$-stimulated EndMT in vitro.

Spironolactone, at a dosage which does not disrupt patient's electrolyte and waterretention balance, inhibited myocardial fibrosis, including left ventricular hypertrophy (LVH) [23]. Spironolactone does not affect basal collagen expression, so it is a safe antifibrotic agent [24]. Consistent with these findings, low or high doses of spironolactone could prevent myocardial fibrosis in rats with unilateral renal ischemia or hyperald osteronism [13]. Fibrosis 


\section{Cellular Physiology Cell Physiol Biochem 2015;36:191-200 \begin{tabular}{l|l|l} 
DOI: 10.1159/000374063 & C 2015 S. Karger AG, Basel
\end{tabular} and Biochemistry Published online: April 30, 2015 \\ Pathway}

in Alport syndrome could be effectively ameliorated with spironolactone therapy, thereby avoiding excessive ECM and, consequently, may delay the evolution of progression of renal fibrosis mediated by the TGF- $\beta$ pathway [25]. Thus, the protective effects of spironolactone are mediated to a large extent by its ability to reverse differentiation and inhibit the subsequent ability of these cells to synthesize collagen, regardless of their origin [26]. Spironolactone plays a crucial role in inhibiting the pathogenesis of tissue fibrosis and effectively stimulates increased gene expression via the EndMT by avoiding the transformation to myofibroblasts.

In our cultured HUVEC cells, suppression of the Notch pathway by DAPT pharmacological inhibition of $\gamma$-secretase markedly ameliorated phenotypic EndMT changes induced by spironolactone. We used the Notch $\gamma$-secretase inhibitor DAPT to block the Notch pathway to determine changes in spironolactone therapy in ameliorating fibrosis in vitro. When the Notch pathway was blocked, HUVECs showed increased mesenchymal-specific cells and regained the protein expression of mesenchymal markers, both inhibited with spironolactone, which supports the Notch signaling pathway participating in the EndMT. Spironolactone treatment ameliorated TGF- $\beta$-induced migration, which was reversed with DAPT pretreatment. Notch1 protein expression was significantly upregulated with spironolactone treatment to suppress TGF- $\beta$-induced EndMT and was markedly reduced with DAPT pretreatment to block the Notch pathway. Notch signaling has a crucial role in regulating vascular endothelial cell differentiation and functional abilities in TGF- $\beta$-induced EndMT, which could be suppressed by spironolactone probably via the overlapped Notch-related cascade response. Spironolactone may have a promising role in preventing and treating fibrosis by modulating the Notch pathway during EndMT especially with TGF- $\beta$ stimulation.

Our results provide additional knowledge in the field, because considering spironolactone with Notch-activity localization differs from previous reports. The Notch $\gamma$-secretase inhibitor ameliorates kidney fibrosis via inhibition of TGF- $\beta / \operatorname{Smad} 2 / 3$ signaling pathway activation [24]. Signaling crosstalk between Notch and TGF- $\beta$ pathways was demonstrated in the early induction of Hey1 expression in Smad3-dependent and Notchindependent or delayed Notch-dependent pathways [8]. Notch signaling is involved in the corneal EndMT process [24]. Notch/Jagged signaling is essential for endothelial function and may contribute to EndMT in embryogenesis and cancer [10]. A high baseline serum level of pro-fibrotic cytokine markers may benefit from spironolactone treatment by limiting ECM turnover and attenuating change in collagen associated with a TGF- $\beta$-activated signaling cascade [27].

In conclusion, our studies are a proof-of-concept of the underlying mechanisms of Notch signaling pathway having biological significance in the EndMT, which would be greatly inhibited by spironolactone. This research may shed new light on new drug regimens for treating EndMT-related fibrosis diseases. Many studies have investigated the vital involvement of the Notch signaling pathway throughout EndMT, but the detailed molecular regulations and the intracellular cascade response activated by spironolactone and TGF- $\beta$ in the process has not been entirely elucidated. Other interactional mechanisms driven by spironolactone in EndMT need further exploration.

\section{Acknowledgement}

This research was supported by the Zhejiang Provincial Natural Science Foundation of China (LY12H02004), the Foundation for the Program of Science and Technology Department of Zhejiang Province of China (2014C33166) and the Foundation for the Program of the Provincial Health Department of Zhejiang Province of China (2014KYA136).

\section{Disclosure Statement}

None.

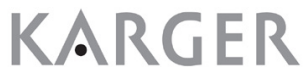




\section{Cellular Physiology Cell Physiol Biochem 2015;36:191-200

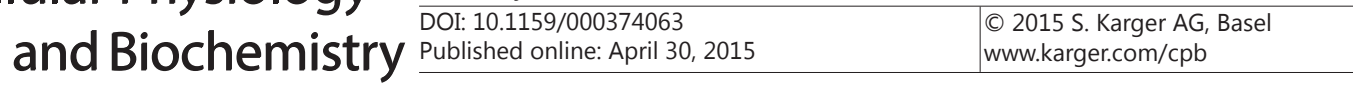 \\ Chen et al.: Spironolactone Protects HUVECs from EndMT Involvement of the Notch-1 Pathway}

\section{References}

1 Piera-Velazquez S, Li Z, Jimenez SA: Role of endothelial-mesenchymal transition (EndoMT) in the pathogenesis of fibrotic disorders. Am J Pathol 2011;179:1074-1080.

2 Yang T, Chen M, Sun T: Simvastatin attenuates TGF- $\beta 1$-induced epithelial-mesenchymal transition in human alveolar epithelial cells. Cell Physiol Biochem 2013;31:863-874.

3 Rieder F, Kessler SP, West GA, Bhilocha S, de la Motte C, Sadler TM, Gopalan B, Stylianou E, Fiocchi C: Inflammation-induced endothelial-to-mesenchymal transition: a novel mechanism of intestinal fibrosis. Am J Pathol 2011;179:2660-2673.

4 Lin F, Wang N, Zhang TC: The Role of Endothelial-Mesenchymal Transition in Development and Pathological Process. Cell Mol Biol 2012;64:717-723.

5 Zeisberg EM, Potenta SE, Sugimoto H, Zeisberg M, Kalluri R: Fibroblasts inkidney fibrosis emerge via endothelial-to-mesenchymaltransition. J Am SocNephrol JASN 2008;19:2282-2287.

6 Samarakoon R, Overstreet JM, Higgins P J: TGF- $\beta$ signaling in tissue fibrosis: Redox controls, target genes and therapeutic opportunities. Cell Signal 2013;25:264-268.

7 Samy Lamouille, Jian Xu, Rik Derynck: Molecular mechanisms of epithelial-mesenchymal transition. Nat Rev Mol Cell Biol 2014;15:178-196.

8 Chen YX, Zheng SP, Qi D, Zheng S, Guo J, Zhang SL, Weng Z-H: Inhibition of Notch Signaling by a $\gamma$-Secretase Inhibitor Attenuates Hepatic Fibrosis in Rats. Plos One 2012;7:e46512.

9 Wang L, Wang YC, Hu XB, Zhang BF, Dou GR, He F, Gao F, Feng F, Liang YM, Dou KF, Han H: Notch-RBP-J Signaling Regulates the Mobilization and Function of Endothelial Progenitor Cells by Dynamic Modulation of CXCR4 Expression in Mice. Plos One 2009;4:e7572.

10 P. Magni, M. Motta: Aldosterone receptor antagonists: Biology and novel therapeutical applications. J Endocrinol Invest 2003;26:788-798.

11 Nemir M, Metrich M, Plaisance I, Lepore M, Cruchet S, Berthonneche C, Sarre A, Radtke F, Pedrazzini T: The Notch pathway controls fibrotic and regenerativerepair in the adult heart. Eur. Heart J 2012;35:2174-2185.

12 Zeisberg EM, Tarnavski O, Zeisberg M, Dorfman AL, McMullen JR, Gustafsson E, Chandraker A, Yuan X, Pu WT, Roberts AB, Neilson EG, Sayegh MH, Izumo S, Kalluri R: Endothelial to mesenchymal transition contributes to cardiac fibrosis. Nat med 2007;8:952-961.

13 Zhang L, Hao JB, Ren L-S, Ding JL, Hao LR: The aldosterone receptor antagonist spironolactone prevents peritoneal inflammation and fibrosis. Lab Invest 2014;94:839-850.

14 Chen H, Sun F, Zhong X, Shao Y, Yoshimura A, Liu Y: Eplerenone-mediated aldosterone blockade prevents renal fibrosis by reducing renal inflammation, interstitial cell proliferation and oxidative stress. Kidney Blood Press Res 2013;37:557-566.

15 Luo JH, Gao XR, Peng LY, Sun HW, Dai G: Effects of hydrochlorothiazide on cardiac remodeling in a rat model of myocardial infarction-induced congestive heart failure. Eur J Pharmacol 2011;667:314-321.

16 Vardeny O, Cavallari LH, Claggett B, Desai AS, Anand I, Rossignol P, Zannad F, Pitt B, Solomon SD: Race Influences the Safety and Efficacy of Spironolactone in Severe Heart Failure. Circ Heart Fail 2013;6:970976.

17 Katsuhito F, Ryozo N: Fibroblast-mediated pathways in cardiac hypertrophy. J Mol Cell Cardiol 2014;70:6473.

18 Zhou H, Chen X, Chen LZ, Zhou X, Zheng GS, Zhang HQ, Huang WJ, Cai JJ: Anti-Fibrosis Effect of Scutellarin via Inhibition of Endothelial-Mesenchymal Transitionon Isoprenaline-Induced Myocardial Fibrosis in Rats. Molecules 2014;19:15611-15623.

19 Fan D, Abhijit T, Jiwon L, Zamaneh K: Cardiac fibroblasts, fibrosis and extracellular matrix remodeling in heart disease. Fibrogenesis\& Tissue Repair 2012;5:15.

20 Zeisberg EM, Potenta S, Xie L, Zeisberg M, Kalluri R: Discovery of endothelial to mesenchymal transition as a source for carcinoma-associated fibroblasts. Cancer Res 2007;67:10123-10128.

21 Ruiz-Ortega M, Rodriguez-Vita J, Sanchez-Lopez E, Carvajal G, Egido J: TGF-beta signaling in vascular fibrosis. Cardiovasc Res 2007;74:196-206.

22 Barter MJ, Pybus L, Litherland GJ, Rowan AD, Clark IM, Edwards DR, Cawston TE, Young DA: HDACmediated control of ERK and PI3K-dependent TGF- $\beta$-induced extracellular matrix-regulating genes. Matrix Biol 2010;29:602-612. 
23 Brilla CG, Matsubara LS, Weber KT: Antifibrotic effects of spironolactone in preventing myocardial fibrosis in systemic arterial hypertension. Am J Cardiol 1993;71:12A-16A.

24 Xiao Z, Zhang J, Peng X, Dong Y, Jia L, Li H, Du J: The Notch $\gamma$-secretase inhibitor ameliorates kidney fibrosis via inhibition of TGF- $\beta /$ Smad2/3 signaling pathway activation. Int J Biochem Cell Biol 2014;55:65-71.

25 Giani M, Mastrangelo A, Villa R, Turolo S, Marra G, Tirelli AS, Hopfer H, Edefonti A: Alport syndrome: the effects of spironolactone on proteinuria and urinary TGF- $\beta 1$. Pediatr Nephrol 2013;28:1837-1842.

26 Li C, Dong F, Jia Y, Du HY, Dong N, Xu YJ, Wang S, Wu HP, Liu ZG, Li W: Notch signal regulates corneal endothelial-to-mesenchymal transition. Am J Pathol 2013;183:786-795.

27 Edgley AJ, Krum H, Kelly DJ: Targeting Fibrosis for the Treatment of Heart Failure: A Role for Transforming Growth Factor- $\beta$. Cardiovasc Ther 2012;30:e30-40. 